\title{
A TECNOLOGIA DA TÊMPERA POR ESTAMPAGEM E SUA RELAÇÃO NO DESENVOLVIMENTO E FABRICAÇÃO DE PRODUTOS
}

\author{
Claudio Pereira Diogo ' \\ Ronaldo Aparecido Souza Cruz ${ }^{2}$ \\ Willy Ank de Morais ${ }^{3,4}$
}

\section{Resumo}

Este trabalho descreve a estampagem a quente seguida de têmpera promovida pela matriz de estampagem. As peças obtidas por esta técnica podem apresentar uma resistência de até I,6GPa, ou seja, bem acima das peças equivalentes, produzidas por meio de estampagem a frio ou obtidas com aços conformáveis de alta resistência. $O$ processo permite efetiva redução de peso em importantes componentes estruturais de segurança do automóvel com qualidade dimensional, grande resistência mecânica e à fratura. Essas características são essenciais a um processo produtivo e eficiente, objetivando a obtenção de um produto seguro, conforme as necessidades impostas pelo INOVARAUTO.

Palavras-chave: Aços; Autopeças; Inovarauto; Estampagem a quente; Aços ao boro; $22 \mathrm{MnB5}$.

\section{PRESS HARDNING TECHNOLOGY AND THEIR RELATIONSHIP WITH DEVELOPMENT AND FABRICATION OF PRODUCTS}

\begin{abstract}
This work describes the hot stamping process and subsequent quenching promoted by the stamping matrix.Parts obtained by this technique can show strength levels until I.6Gpa, therefore far above of the similar parts obtained by cold stamping or by the employment of high strength steels. The process allows effective weight reduction in major structural and safety car componentes, dimensional quality, high mechanical strength and fracture toughness, these characteristics essential to an efficient production process and to produce a safe product, thus meeting the needs imposed by INOVARAUTO.
\end{abstract}

Keywords: Steels; Autoparts; Inovarauto; Hot stamping; Boron steel; $22 \mathrm{MnB5}$.

\section{INTRODUÇÃO}

Dentre as várias linhas de modernização da indústria automobilística, três pontos serão destacados neste trabalho: (I) redução do impacto ambiental, (2) melhoria de segurança e (3) modernização de processos. Soluções surgidas a partir destas demandas têm impactado a produção de novos automóveis, inclusive nos processos e materiais envolvidos.

\section{I.I Redução do Impacto Ambiental}

Com o incremento da poluição nos grandes centros urbanos e com o impacto no aquecimento global, atualmente a indústria automobilística tem como principal objetivo reduzir o chamado "rastro de carbono" (carbon footprint) de seus automóveis. Esse impacto ambiental nos automóveis ocorre nas três etapas de sua vida: fabricação, uso e descarte do produto. As principais técnicas empregadas para reduzir o rastro de carbono de um automóvel, durante a sua fabricação e descarte, se baseiam na intensificação do uso de materiais avançados, adoção de materiais mais recicláveis e o emprego de processos produtivos mais racionais. O consumo de combustível, com a consequente emissão de gases de escapamento (tailpipe emissions), é o principal responsável pela geração de impacto ambiental, causado por um automóvel ao longo de sua vida útil.

O consumo de combustível de um automóvel está, principalmente, associado à eficiência dos seus sistemas de propulsão e transmissão, simplificadamente, conhecidos como "powertrain". O peso total do veículo (partes mecânicas e carroceria) é o segundo item que mais colabora na emissão de poluentes. A aerodinâmica, apesar da sua aparente

\footnotetext{
'ACEBRAS Ferro e Aço, Timóteo, MG, Brasil.

${ }^{2}$ FERROLENE S/A, São Paulo, SP, Brasil.

${ }^{3}$ Faculdade de Engenharia, Universidade Santa Cecília - UNISANTA, Santos, SP, Brasil. E-mail: willyank@unisanta.br ${ }^{4}$ INSPEBRAS, Praia Grande, SP, Brasil.
} 
influência, tem uma importância secundária neste aspecto, especialmente em veículos de uso urbano, dos quais deseja-se uma maior redução na emissão de poluentes. É possível reduzir o peso do veículo nos seus equipamentos (motor, transmissão, eixos, etc.) ou na sua carroceria. No caso da carroceria, esta equivale a aproximadamente $1 / 4$ do peso total do veículo. Neste caso, o ganho em peso é diretamente proporcional ao aumento de resistência das chapas empregadas [I].

\section{I.2 Melhoria da Segurança}

Por outro lado, no Brasil os níveis de segurança para motoristas e passageiros estão cada vez mais rigorosos, particularmente depois da criação do Latin NCAP. De forma a atender às exigências de segurança, uma solução, cada vez mais consolidada, é o emprego de estrutura automotiva mista. Na estrutura de um automóvel seguro, existem duas regiões, com comportamentos mecânicos antagônicos, que atuam em perfeita harmonia entre si, durante um acidente. Essas regiões são:

a) Estrutura periférica deformável, que irá absorver e dissipar a energia de um acidente através de sua deformação plástica, assim reduzindo os danos que poderiam ser impostos aos ocupantes de um veículo conforme ilustrado na Figura la.

b) Célula de sobrevivência indeformável: responsável por evitar que os ocupantes do veículo sejam atingidos pela deformação periférica do mesmo, preservando a sua integridade física, conforme ilustrado na Figura Ib.

\section{I.3 Modernização dos Processos}

É cada vez mais necessário que os processos de produção atendam mais rapidamente, com menor custo e maior precisão, as demandas do setor automotivo (excelência, agilidade e pontualidade). Os componentes automobilísticos precisam apresentar um controle dimensional muito apurado para ser enquadrado nos atuais processos de produção. Pequenas diferenças podem inviabilizar o uso do componente.

De forma a viabilizar a diminuição da espessura dos componentes automobilísticos, suas geometrias vão se tornando mais complexas, de forma a compensar mecanicamente a perda da rigidez destes componentes, em relação aos componentes mais espessos. Vincos, dobras e protuberâncias são características geométricas que aumentam mecanicamente a rigidez dos automóveis, permitindo o emprego de componentes mais finos. Por isso, tais características estão cada vez mais presentes nos novos veículos.

Menor quantidade de peças a serem montadas tornam a estrutura mais robusta e rígida, assim como menos susceptível a vibrações e ruídos que podem aparecer ao longo do seu uso. Em paralelo uma menor quantidade de soldas ou juntas parafusadas/rebitadas tornam a montagem do automóvel mais rápida, eficiente (menos propensa a falhas na montagem ou no uso) e, obviamente, mais barata.

\section{I.4 Opções Tecnológicas - Aços de Alta Resistência Mecânica}

É relativamente comum o emprego do termo "aços leves" para aplicações automobilística, porém este termo é incorreto. Um aço mais resistente ainda possui a mesma massa específica, que vale aproximadamente $7,85 \mathrm{~g} / \mathrm{cm}^{3}$ para aços ferríticos [4]. Porém empregando-se aços mais resistentes é possível fazer um mesmo componente estrutural mais fino, ainda suportando o mesmo nível de carregamento. Desta forma, o componente e a estrutura como um todo se tornam mais leves pelo menor uso do aço, que possui praticamente o mesmo peso de um aço comum.

Apesar do grande potencial de redução de peso, o emprego de aços de alta resistência apresenta algumas limitações, que podem ser resumidas desta forma [I]:

- Aços mais caros: o custo de aços com graus de resistência da ordem de $800 \mathrm{MPa}$ chega a ser até $50 \%$ mais elevado do que um aço comum (tipo SAE I0I2).
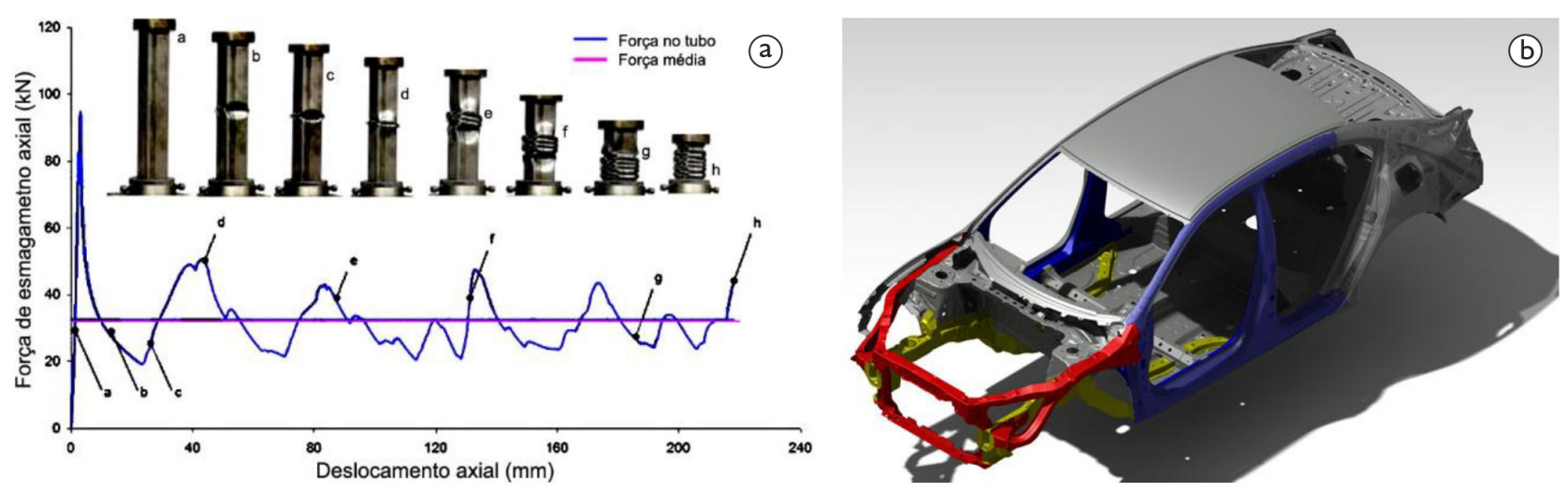

Figura I. Mecanismos de segurança mecânica presentes nos automóveis modernos: (a) componente estrutural perfurado que se deforma estavelmente sob compressão [2]; (b) estrutura de deformação progressiva (em vermelho) e célula de sobrevivência (em roxo) [3]. 
Muitas vezes a economia no peso final pode ser maior, mas o preço inicialmente mais elevado sempre será um paradigma a ser superado.

- Aços de menor disponibilidade: por serem fabricados para demandas muito específicas, a quantidade e dimensões disponíveis são poucas; além do fabricante (siderúrgica) produzir uma quantidade mínima para que o aço seja economicamente viável. E o mercado deve estar preparado ou estar em um estágio de desenvolvimento tal que viabilize a disponibilidade deste novo aço.

- Aços mais difíceis de se trabalhar: estes apresentam grandes dificuldades na conformabilidade (para corte, dobra e estampagem), especialmente a frio, limitando as geometrias das peças que podem ser obtidas. Para o trabalho com estes aços são necessárias mais etapas de conformação para distribuir as deformações impostas de maneira mais homogênea e suportável. Neste caso, normalmente são empregadas prensas com processo de transferência (transfer). Peças com geometrias mais complexas só podem ser obtidas com aços menos resistentes, que apresentem conformabilidade necessária, gerando peças mais espessas e, consequentemente, mais pesadas [5].

- Aços com maior retorno elástico: o grau de resistência mais elevado dos aços de alta resistência, com relação elástica mais próxima à unidade, torna o controle dimensional mais complexo, pois o retorno elástico é mais intenso nesses aços. O retorno elástico dificulta a obtenção de dimensões e ângulos precisos em peças conformadas. Este fenômeno é tanto mais intenso quanto maior for o grau de resistência do aço e menor sua espessura, que são exatamente as duas características mais desejáveis para estes aços, nesta aplicação $[5,6]$.

\subsection{Opções Tecnológicas - Novos Materiais}

Novos materiais com desempenho superior ao aço em muitas aplicações já são empregados na indústria automobilística. Em especial, merecem destaque os polímeros, empregados no revestimento interno (painéis) e algumas partes da carroceria (grades, laterais, acessórios). Resinas de polióxido de fenileno (PPO + PA), para para-lamas e painéis de carrocerias, reduzem o peso em até $50 \%$, se comparado ao aço e ainda permitem a pintura da peça na linha de montagem, sem o uso de primer [7]. Porém a substituição do material de um componente estrutural por outro material, além dos desafios em termos de projeto e ciclo produtivo, ainda é visto com muito receio e preconceito, especialmente entre os usuários finais dos veículos.

O aço é o material mais pesquisado pela humanidade, e mesmo assim existe muita coisa a se descobrir. $O$ grau de aprofundamento no conhecimento de um novo material é proporcional ao tipo de material e ao grau de inovação na substituição do aço. Os principais candidatos à substituição o aço estão, em ordem: alumínio, ligas leves (por exemplo baseadas no Magnésio), ligas avançadas (por exemplo baseadas no titânio) e compósitos fibrosos (de fibra de vidro, carbono e kevlar). $O$ desenvolvimento destes é demorado, pois não apenas o material deve ser estudado e caracterizado, como também o desempenho do componente deve ser avaliado e o processo produtivo equacionado, de forma a tornar econômica a aplicação do novo material.

\section{I.6 Opções Tecnológicas - Novos Processos de Produção}

A indústria automobilística possui uma dinâmica global, assim as boas inovações são rapidamente difundidas neste setor, gerando novos métodos de produção que são incorporados na cadeia produtiva. Nos últimos anos, por exemplo, foi introduzido e consolidado no Brasil o uso de blanks soldados a laser (tailored blanks), a partir de uma demanda oriunda de fabricantes que já empregavam componentes produzidos com esta tecnologia.

Existem novas e diferentes tecnologias disponíveis, dentre estas a estampagem a quente, que já é conhecida de longa data. Porém, no caso da estampagem a quente, o seu desenvolvimento só se iniciou recentemente no Brasil, especialmente devido à demanda. Mesmo assim com a necessidade de importação de máquinas, equipamentos e até mesmo matéria-prima para torná-la viável.

Os novos processos, por melhores que sejam, sempre necessitarão de adaptações e/ou ajustes por parte de quem os utiliza. Treinamentos, mudanças de lay-out são alguns itens que, dentre outros, costumeiramente, necessitam ser revistos. Neste sentido, o INOVARAUTO e a instalação de novas montadoras de automóveis mais sofisticados terão muito a contribuir como força motriz.

\section{ESTAMPAGEM A QUENTE}

A estampagem a quente com têmpera promovida pela matriz (também conhecida como "press hardening") surgiu no final dos anos 90 pelo emprego de aços ao boro para produzir componentes automobilísticos simples, como reforços de portas e para-choques [5]. A Figura 2 ilustra os tipos de componentes produzidos.

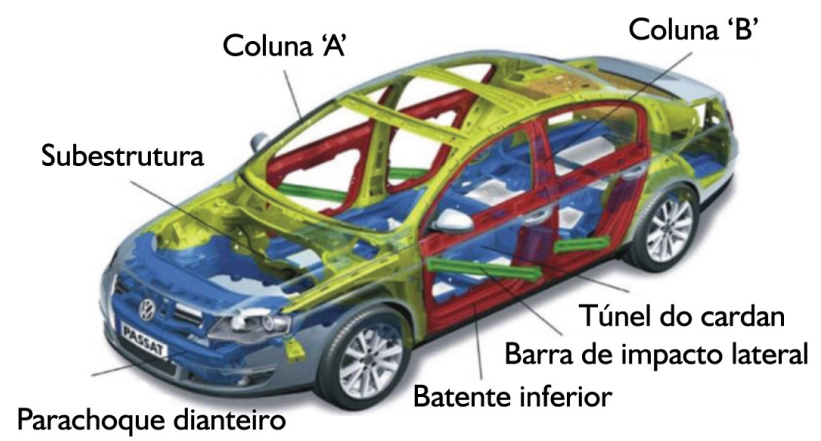

Figura 2. Aplicações de peças produzidas por estampagem a quente [8]. 


\section{I Aços Empregados}

São empregados aços com teores de carbono intermediários aos aços de estampagem e aços de construção mecânica. Suas composições químicas são similares aos aços-carbono SAE, da norma J403, apresentadas na faixa 'B' da Tabela I. Em relação a estes aços são feitas adições de manganês e boro (e eventualmente cromo) para otimizar os resultados após têmpera. Estes aços são conhecidos pela antiga notação DIN, sendo o mais comum o $22 \mathrm{MnB5}$ $(0,22 \% \mathrm{C} ; 1,25 \% \mathrm{Mn}$ e 0,0050\%B), mas também empregados os aços $27 \mathrm{MnCrB5}$ e $37 \mathrm{MnB} 4$ [10].
Aços do tipo 22MnB5 [I I] podem ser empregados para produzir partes complexas, resistentes e tenazes, empregadas, por exemplo, em barras de proteção e colunas de automóveis. As peças podem apresentar uma resistência de até I,6GPa, nível de resistência que está bem acima do que poderia ser obtida com aços comuns, através de estampagem a frio e dos aços conformáveis de alta resistência mecânica.

A estampagem dos aços ocorre em uma faixa de temperaturas entre $650^{\circ} \mathrm{C}$ e $850^{\circ} \mathrm{C}$, dentro das quais o aço apresenta uma grande plasticidade, conforme ilustrado na Figura 3. Um blank pode ser conformado, desta forma, em uma geometria complexa em uma única operação.

Tabela I. Composições químicas simplificadas e propriedades mecânicas após têmpera de aços carbono comuns da norma SAE J403 família $10 X X[4,9]$

\begin{tabular}{|c|c|c|c|c|c|c|c|}
\hline \multirow[t]{2}{*}{ Faixa } & \multirow{2}{*}{$\begin{array}{c}\text { SAE J403 } \\
\text { grau }\end{array}$} & \multicolumn{2}{|c|}{ Elementos de Liga Principais } & \multirow{2}{*}{$\% \mathbf{C}_{\text {médio }}$} & \multicolumn{3}{|c|}{$\begin{array}{c}\text { Propriedades recomendáveis após Têmpera } \\
(90 \% \text { Martensita })\end{array}$} \\
\hline & & $\% \mathbf{C}$ & $\% M n$ & & $\mathbf{H R}_{\mathrm{c}}$ & HB & $\mathrm{S}_{\mathrm{LR}}(\mathrm{MPa})$ \\
\hline \multirow{5}{*}{$\varangle$} & 1015 & 0,13 a 0,18 & 0,30 a 0,60 & 0,155 & 35,5 & 331 & 1122 \\
\hline & 1016 & & 0,60 a 0,90 & 0,155 & 35,5 & 331 & 1122 \\
\hline & 1017 & 0,15 a 0,20 & 0,30 a 0,60 & 0,175 & 37,5 & 349 & 1181 \\
\hline & 1018 & & 0,60 a 0,90 & 0,175 & 37,5 & 349 & || $8 \mid$ \\
\hline & 1019 & & 0,70 a $I, 00$ & 0,175 & 37,5 & 349 & 1181 \\
\hline \multirow{6}{*}{$\infty$} & 1020 & 0,18 a 0,23 & 0,30 a 0,60 & 0,205 & 40 & 373 & 1259 \\
\hline & $102 \mid$ & & 0,60 a 0,90 & 0,205 & 40 & 373 & 1259 \\
\hline & 1022 & & 0,70 a $I, 00$ & 0,205 & 40 & 373 & 1259 \\
\hline & 1023 & 0,20 a 0,25 & 0,30 a 0,60 & 0,225 & $4 I, 5$ & 387 & 1310 \\
\hline & 1025 & 0,22 a 0,28 & & 0,25 & 43,5 & 408 & 1383 \\
\hline & 1026 & & 0,60 a 0,90 & 0,25 & 43,5 & 408 & 1383 \\
\hline \multirow{6}{*}{$U$} & 1029 & 0,25 a 0,31 & 0,60 a 0,90 & 0,28 & 45 & 425 & 1442 \\
\hline & 1030 & 0,28 a 0,34 & & 0,31 & 46,5 & 442 & 1505 \\
\hline & 1033 & 0,30 a 0,36 & 0,70 a $I, 00$ & 0,33 & 47,5 & 455 & $|55|$ \\
\hline & 1035 & 0,32 a 0,38 & 0,60 a 0,90 & 0,35 & 48,5 & 467 & 1599 \\
\hline & 1037 & & 0,70 a $I, 00$ & 0,35 & 48,5 & 467 & 1599 \\
\hline & 1038 & 0,35 a 0,42 & 0,60 a 0,90 & 0,385 & 50 & 488 & 1675 \\
\hline
\end{tabular}

HRC - Dureza Rockwell escala "C”; HB - Dureza Brinell; SLR - Limite de Resistência em tração.
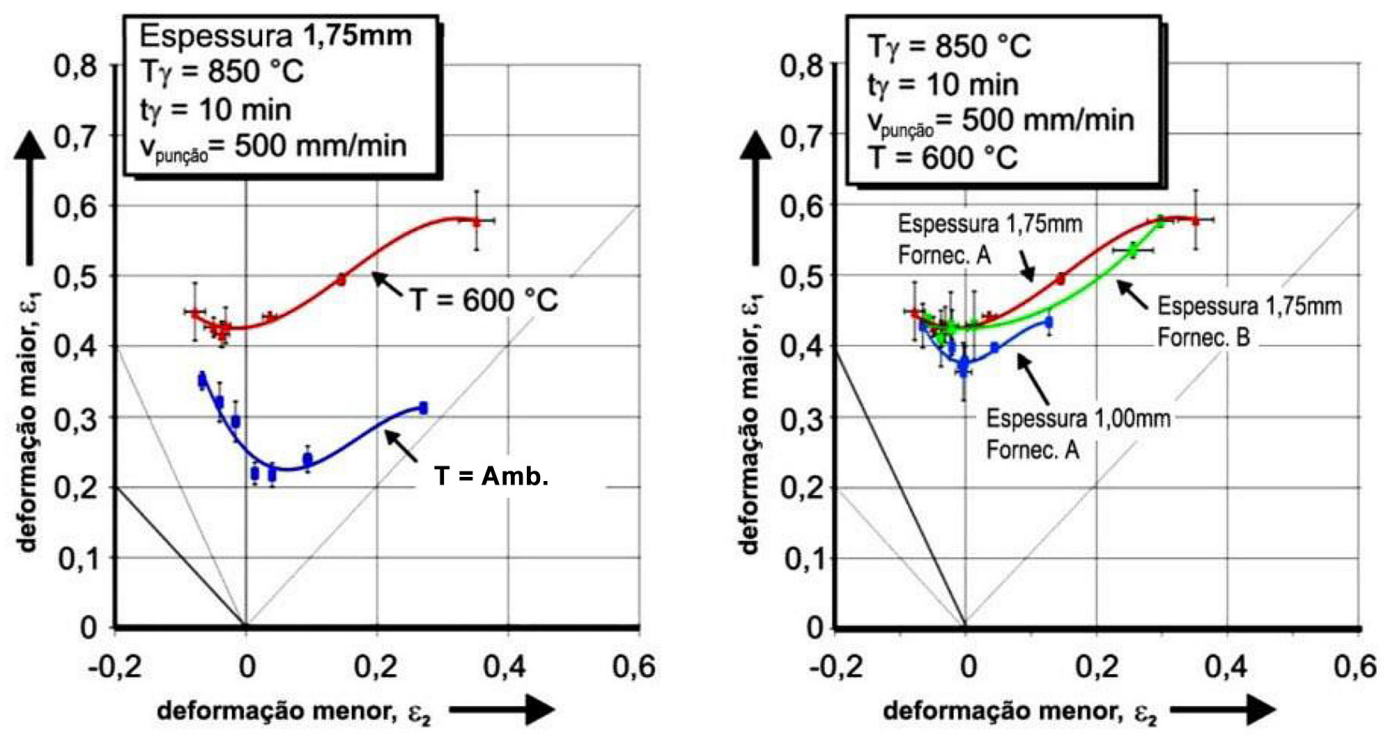

Figura 3. Curvas Limites de Conformação (CLC) de aços $22 \mathrm{MnB} 5$ recobertos com liga de Al-Si [I2]. 
Porém, nesta condição, o aço apresenta baixa capacidade de estiramento, devido à diminuição de sua capacidade de encruamento. Por isso pode ser necessária uma operação prévia de conformação.

O efeito das adições a mais de Manganês e Boro presentes no aço $22 \mathrm{MnB5}$ pode ser visto na Figura 4. Esta figura descreve a distribuição de propriedades mecânicas em uma chapa de $5 \mathrm{~mm}$ de espessura; maior espessura tipicamente empregada neste processo, após têmpera em água. A temperatura de formação da martensita no resfriamento (MS), que é um importante parâmetro para controle do processo, pode ser estimada pela composição química através de várias equações, tais como a Equação I [ I l]:

$$
\begin{aligned}
& \mathrm{MS}=499-308 \% \mathrm{C}- \\
& 32,4 \% \mathrm{Mn}-27 \% \mathrm{Cr}- \\
& 16,2 \% \mathrm{~N} \mathrm{i}-10,8(\% \mathrm{Si}+\% \mathrm{Mo}+\% \mathrm{~V})+ \\
& 10 \% \mathrm{Co}
\end{aligned}
$$

$A$ adição de $M n$ e $B$ é estratégica para tornar as propriedades mecânicas mais homogêneas, ao longo da espessura da peça, mesmo na região central, onde a

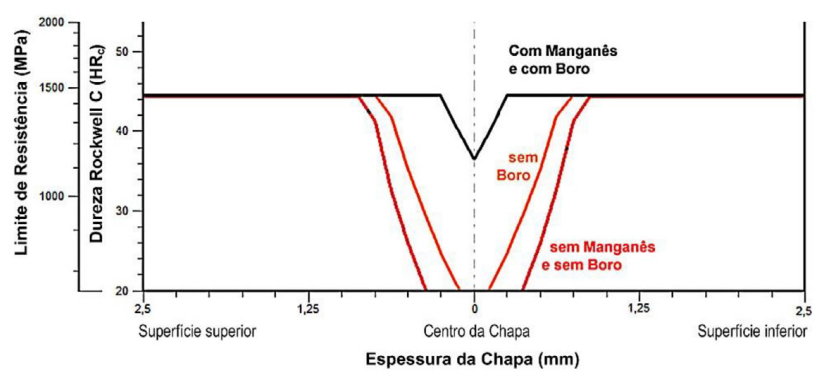

Figura 4. Distribuição de dureza $\left(H R_{c}\right)$ e de Limite de Resistência $\left(\mathrm{S}_{\mathrm{LR}}\right)$ em relação à linha central de uma chapa de aço com $5 \mathrm{~mm}$ de espessura. A composição base: $0,22 \% \mathrm{C} ; 0,80 \% \mathrm{Mn}$ e $0,15 \% \mathrm{Si}$. Composição: I,20\%Mn e 0,0030\%B (em aço com 0,0050\%N). Dados calculados através de [10

(a)

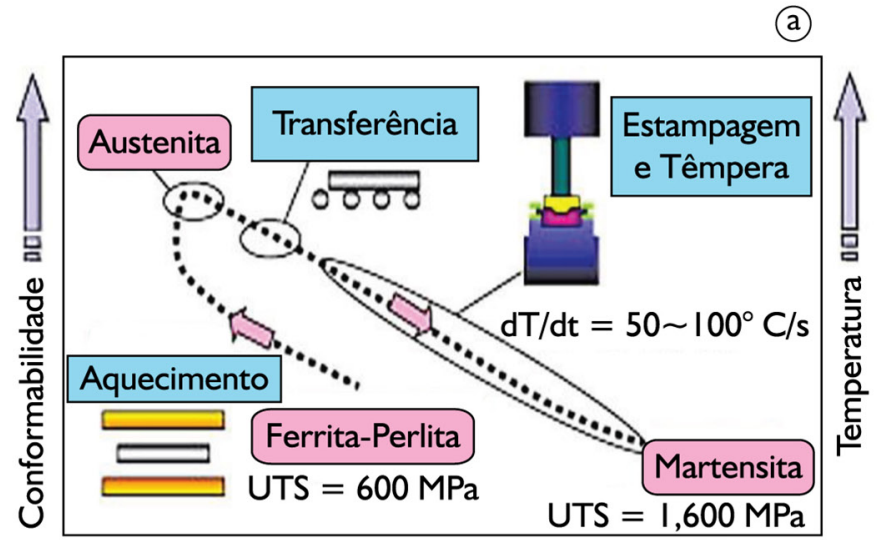

Limite de resistência 10 efetividade do resfriamento por têmpera é menor, como mostrado na Figura 4. Ademais, o Mn auxilia na austenitização do aço. Quando adicionado o Cromo tem um efeito similar ao $\mathrm{Mn}$, em termos de temperabilidade. Porém como é elemento ferrogêneo, este não é favorável para a etapa do aquecimento, sendo preterido em relação ao $\mathrm{Mn}$, que também é mais barato. $O$ teor de carbono define o grau de resistência do aço após a têmpera. Como não é desejável o mesmo nível de resistência mecânica dos aços ferramenta, o teor de carbono é mais baixo.

\subsection{Processo}

Blanks de aço para estampagem a quente são inicialmente austenitizados em temperaturas entre $900^{\circ} \mathrm{Ce} 950^{\circ} \mathrm{C}$ durante alguns minutos (de 5 a $10 \mathrm{~min}$.) em fornos geralmente contínuos e com atmosfera controlada [8]. Como a espessuras dos blanks é relativamente pequena, o aquecimento gera uma estrutura austenítica relativamente homogênea em toda a peça, mesmo em um tempo tão curto [6].

Devido às limitações de estiramento do aço na estampagem a quente, peças preconformadas podem ser empregadas no lugar dos blanks planos [5,6, I I]. Imediatamente após sair do forno, o blank é transferido, conforme ilustrado na foto da Figura $5 \mathrm{a}$, para a prensa onde este é conformado a quente através de matrizes resfriadas. O resfriamento ocorre pela troca de calor entre a peça e as matrizes que ocorre ainda sendo exercida pressão de estampagem. Como o aço deve estar na estrutura austenítica durante o processo de conformação, este deve terminar em temperaturas acima da temperatura de formação da martensita $\left(M_{\mathrm{s}}\right)$ do aço (Equação I).

O tempo total do resfriamento depende da espessura da peça obtida, após completada a deformação induzida na estampagem. Durante este período de tempo, a peça conformada é resfriada nas matrizes. O resfriamento internamente realizado com água objetiva o obter taxas de resfriamento de $50 \mathrm{a} 100^{\circ} \mathrm{C} / \mathrm{s}$, até completar a têmpera.

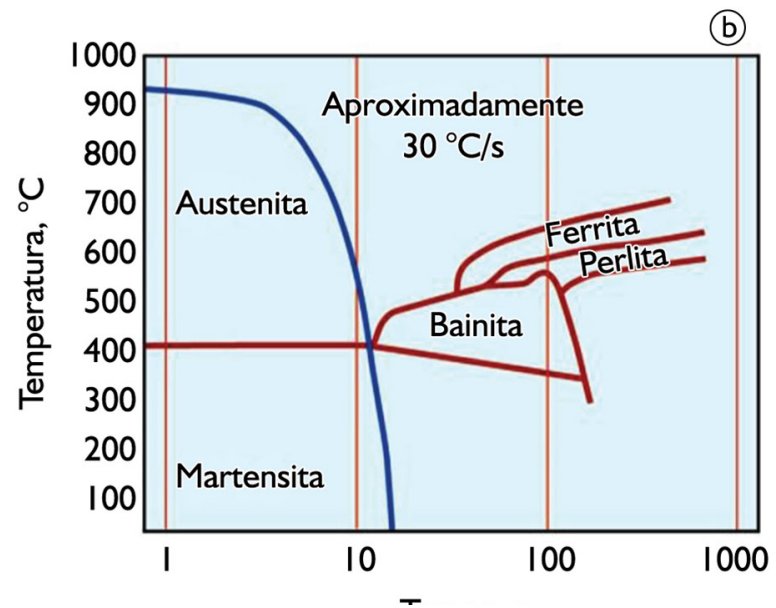

Figura 5. Estampagem a quente: (a) ciclo térmico e microestrutural do processo e (b) evolução ideal da temperatura, em função do tempo em uma curva CCT típica destes aços [5]. 
Finalmente a peça conformada é extraída da prensa a uma temperatura em torno de $150^{\circ} \mathrm{C}$ e já apresentando uma alta resistência (limite de resistência e de escoamento por volta de I,5GPa e I, I GPa, respectivamente). A variação microestrutural e das características mecânicas do aço ao longo do processo variam conforme descritas a seguir e apresentado na Tabela 2.

A representação na Tabela 2 ilustra que:

a) A estrutura inicial é constituída de ferrita e perlita. Como o aço foi laminado a quente em condições para apresentar uma melhor conformabilidade, a microestrutura apresenta um certo bandeamento (Tabela 2a);

b) Após aquecimento no forno, a uma temperatura de cerca de $925^{\circ} \mathrm{C}$, a estrutura torna-se homogeneamente austenítica. A conformabilidade do blank aumenta consideravelmente [12], permitindo ser moldado em geometrias complexas; c) Durante o tempo que pode variar de 15 a 30 segundos, em função da espessura da peça obtida, o aço resfria rapidamente, de 50 a $100^{\circ} \mathrm{C} / \mathrm{s}$ sob condições de têmpera, conforme ilustrado na Figura 5b. Devido à composição química, a austenita transforma-se em martensita que apresenta uma alta resistência.

\subsection{Oxidação (Carepas)}

A oxidação da chapa de aço (blank ou peça predeformada a frio) é evitada no aquecimento quando o forno tem uma atmosfera controlada. Porém, na etapa de transferência da chapa para a prensa, durante a saída do forno e o contato com as matrizes resfriadas, o aço oxida-se ao ar, formando uma camada irregular de óxido. Esta carepa gerada possui uma dureza mais elevada e produz desgaste nas matrizes, reduzindo a sua vida útil.

O contato da chapa de aço com o oxigênio do ar nesta etapa também promove um descarbonetação superficial que

Tabela 2. Variações microestruturais e de propriedades mecânicas de aços ao longo da execução do processo de estampagem à quente

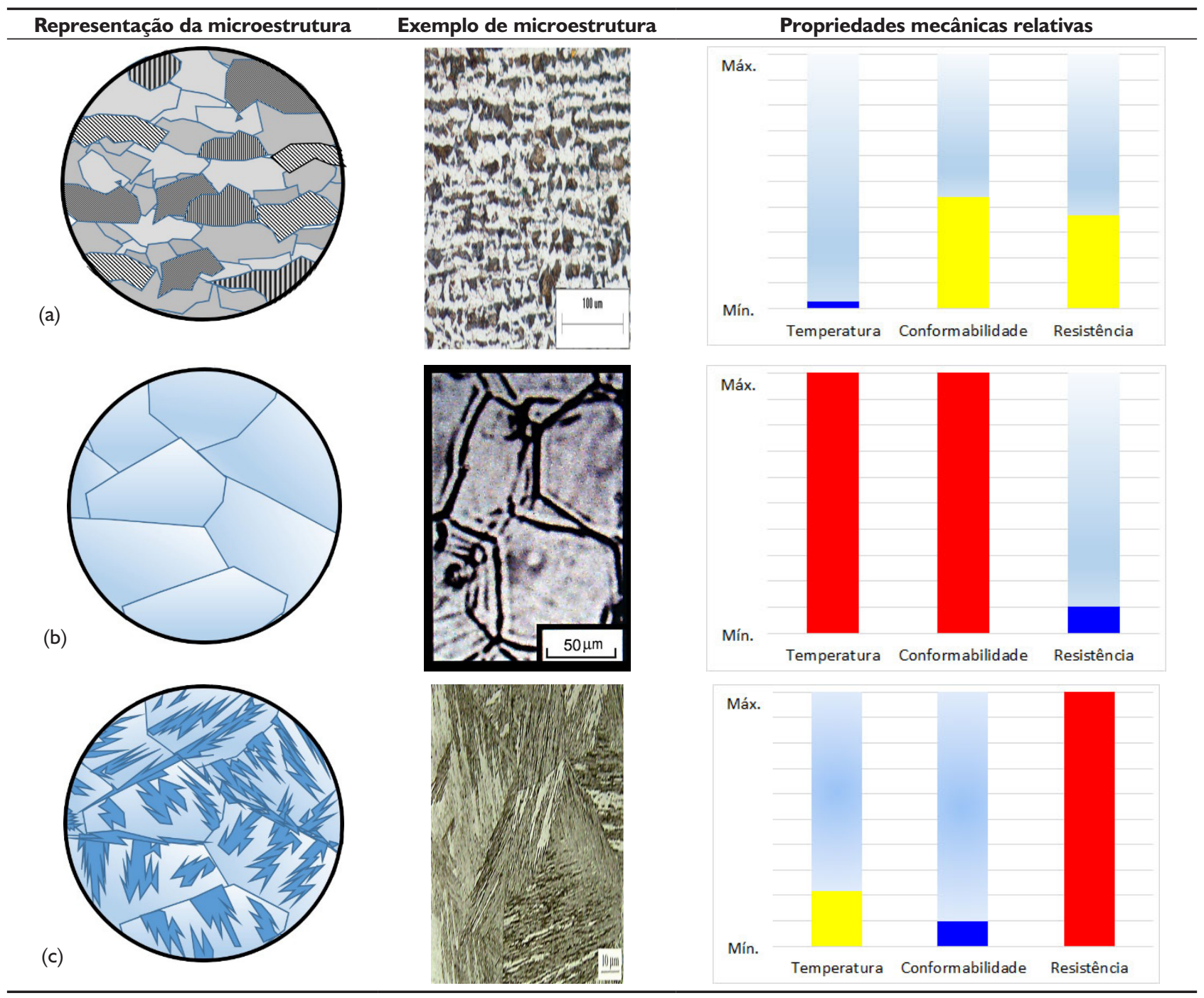


pode alcançar até $60 \mu \mathrm{m}$. Esta descarbonetação prejudica as propriedades mecânicas finais do componente. Para a retirada dos óxidos formados é empregada uma operação de jateamento (shotblaster). Porém esta é uma operação que além de acarretar custo pode ser prejudicial ao acabamento e às tolerâncias geométricas da peça acabada.

A solução para evitar este problema é o emprego de aços recobertos com ligas protetoras, especialmente Al-Si [II], conforme ilustrado na Figura 6. Durante o aquecimento, este revestimento protetivo é transformado em uma camada de liga Fe-Al-Si que é altamente aderente ao substrato e apresenta boa resistência à corrosão [10]. Após a operação, as peças podem ser pintadas diretamente, sem jateamento.

\section{TENDÊNCIAS}

A faixa de resistência mecânica obtida, entre $600 \mathrm{MPa}$ a I,5GPa para o limite de resistência $\left(\mathrm{S}_{\mathrm{LR}}\right)$ e a ductilidade, descrita por valores de alongamentos em tração de 20 a $6 \%$ [I I], levam ao material a apresentar uma grande resistência à fratura (tenacidade). Assim, o comportamento mecânico do aço após a estampagem é propício à absorção de energia por deformação plástica [I].

O gráfico da Figura 7 ilustra $\circ$ posicionamento deste comportamento do material estampado a quente em relação a outras ligas de engenharia. Ressalta-se que o aço empregado no processo de estampagem a quente praticamente não possui elementos de liga (além do C, Mn,

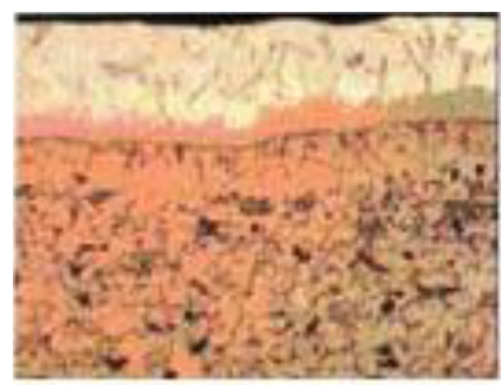

Camada e chapa após aquecimento sem conformação.

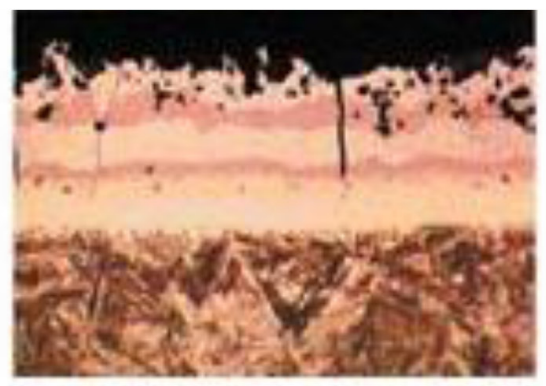

Camada e chapa após aquecimento e estampagem a quente.

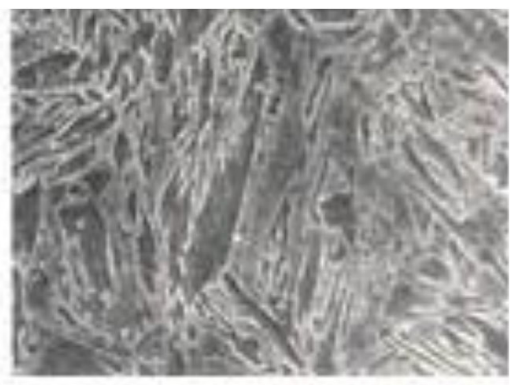

Camada de Al-Si antes do aquecimento.

Figura 6. Aspecto microestrutural da superfície de uma chapa empregada no processo de estampagem a quente que conta com a proteção de uma camada de liga Al-Si [5].

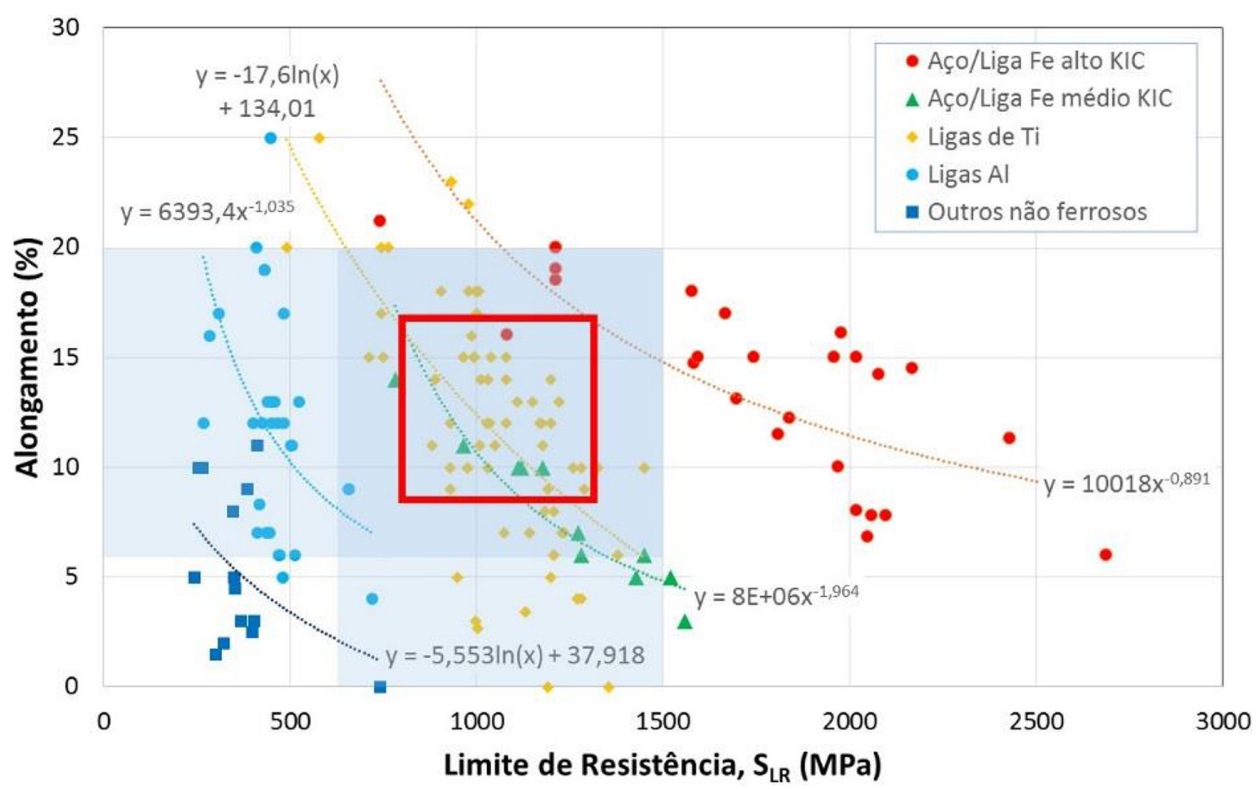

Figura 7. Relação entre ductilidade (representada pelo alongamento) e resistência (representada pelo limite de resistência) obtidos em ensaios de tração de inúmeras ligas de engenharia em relação à faixa obtida com os aços estampados à quente. Gráfico produzido com dados obtidos em [10]. 
$\mathrm{B}$ e, eventualmente, $\mathrm{Cr}$ ), em relação aos demais materiais comparados na Figura 7.

A estampagem a quente já é empregada em alguns países, nos quais estão disponíveis equipamentos e tecnologias para tal. Permite efetiva redução de peso em importantes componentes estruturais de segurança do automóvel, como as colunas "A" e "B" [5]. Além da qualidade dimensional, estas partes requerem grande resistência mecânica e à fratura, essenciais ao um processo produtivo eficiente e para obter um produto seguro. Um exemplo disso são as colunas "A" e "B", que são as principais partes estruturais da "célula de sobrevivência" de um automóvel (ver item I.2.b), ilustradas na Figura 8 [13].

Para se ter uma ideia do incremento do processo de estampagem a quente, em 2004 o consumo estimado de aços ao boro para estampagem à quente era de cerca de $70 \mathrm{mil}$ toneladas por ano na Europa. Cinco anos depois, o consumo aumentou para cerca de 300 mil toneladas. Japão e Estados Unidos estão seguindo esta tendência [5]. Adicionalmente, a produção de veículos automotores está ocorrendo uma grande expansão nos países emergentes, especialmente nos chamados BRICS (Brasil, Rússia, Índica, China e África do Sul), como mostrado no gráfico da Figura 9 [14].

Com a maior produção, haverá uma demanda proporcionalmente maior de novas tecnologias que, no caso em particular do Brasil, serão incentivadas pelo INOVAR-AUTO,
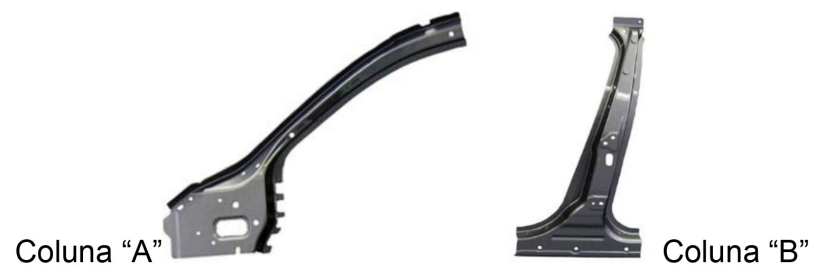

Figura 8. Componente estruturais importantes da carroceria de um automóvel que estão sendo fabricados pelo processo de estampagem a quente [13].

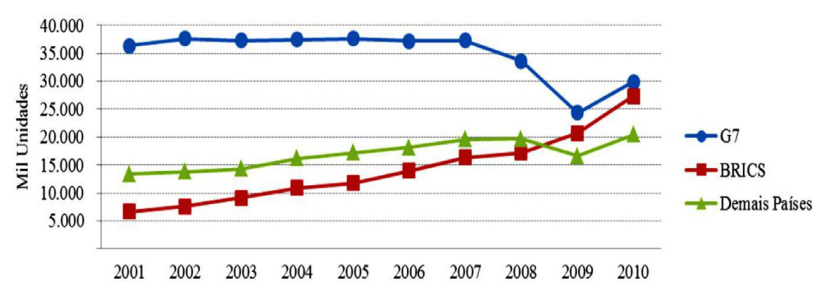

Figura 9. Evolução recente da produção mundial de veículos automotores [14]. novo regime automotivo de promoção da competitividade da indústria automotiva nacional. Destas novas tecnologias, o processo de estampagem a quente encontra-se entre os mais promissores, inclusive sendo motivo de divulgação de seu uso na produção de parte estruturais dos mais recentes lançamentos automobilísticos.

O emprego da estampagem a quente foi, inclusive, destacado na divulgação das características de um novo veículo lançado recentemente [15]. Apesar deste automóvel contar com $76 \%$ de sua estrutura construída de aços de alta e ultra alta resistência mecânica, o emprego de peças estampadas a quente foi um dos principais motivos apontados pelos maiores níveis de segurança e economia alcançadas pelo veículo [I5].

Em termos nacionais o aço já é produzido pelas siderúrgicas, mas existe a necessidade de desenvolvimento de fornecedores de chapas/bobinas deste aço para menores quantidades. Além disso, o aço adequado para a estampagem a quente não é produzido no Brasil com o revestimento superficial protetivo (liga Al-Si) adequado. Porém, recentemente uma siderúrgica multinacional anunciou investimentos para o fornecimento ao mercado deste material [16].

\section{CONCLUSÕES}

A estampagem a quente é uma técnica que começou a ser desenvolvida industrialmente nos anos 90 e agora está sendo incorporada no país. A produção de componentes a partir da estampagem a quente apresenta diversas vantagens em termos econômicos e de desempenho. Basicamente um aço relativamente simples é processado de forma a serem obtidos componentes (autoparts) de alta resistência e tenacidade. Estes componentes têm impactado de forma positiva no desempenho dos novos lançamentos automobilísticos com testes de impacto (crash tests) do Latin NCAP. Apesar de ainda existirem algumas limitações em termos de fornecimento de matéria-prima, os investimentos que já estão sendo feitos estão proporcionando a consolidação da técnica no país.

\section{Agradecimentos}

Os autores agradecem a recepção e apoio dos técnicos da FERROLENE S/A no acompanhamento das práticas operacionais do processo de estampagem a quente na empresa.

\section{REFERÊNCIAS}

I Morais WA, Borges HC. Condições técnico-econômicas para viabilizar o emprego de aços planos de elevada resistência mecânica em aplicações práticas. Tecnologica em Metalurgia, Materiais e Mineração. 2009;6(I):I-6. http://dx.doi.org/10.4322/tmm.0060I00I.

2 Bodlani SB, Yuen CK, Nurick GN. The energy absorption characteristics of square mild steel tubes with multiple induced circular hole discontinuities - Part I: experiments. Journal of Applied Mechanics. 2009;76(4):360-37I. 
Diogo; Cruz; Morais

3 Boron Extrication. 2013 Honda Accord body structure. 2014 [acesso em 7 mar. 20I4]. Disponível em: http:// boronextrication.dev.fireemsblogs.com/tag/honda/.

4 Morais WA, Fernandes AA, Costa AK, Borges HC. Revisão das principais características que definem as aplicações de aços planos não ligados. In: Associação Brasileira de Metalurgia, Materiais e Mineração. Anais do $67^{\circ}$ Congresso da ABM; 2012 Julho 3I-Agosto 3; Rio de Janeiro, Brasil. São Paulo: ABM; 20I2. p. 266I-2673.

5 Altan T. Hot-stamping boron-alloyed steels for automotive parts. 2006 [acesso em 10 jan. 20 I4]. Disponível em: http://www.thefabricator.com/article/stamping/hot-stamping-boron-alloyed-steels-for-automotive-parts.

6 Kusumi K, Nomura N, Maki J. Formability and FEM simulation of steel sheets in the hot stamping process. Nippon Steel Technical Report. 2013;May:47-54.

7 Saudi Basic Industries Corporation - SABIC. Veículo mais leves. 2014 [acesso em I abr. 20I4]. Disponível em: https://www.sabic-ip.com/gep/pt/AboutUs/SustainabilitySolutionsDetail/automotiveweightout.html.

8 Karbasian H, Tekkaya AE. A review on hot stamping. Journal of Materials Processing Technology. 2010;210(I5):2103-21 I8. http://dx.doi.org/10.1016/j.jmatprotec.2010.07.019.

9 ASM International. SteCal: low-alloy steels: their properties and how to obtain them. Version 3.0.3. Materials Park; 2004.

10 MATWEB. Material Property Data. 2014 [acesso em 26 fev. 20I4]. Disponível em: http://www.matweb.com/search/ PropertySearch.aspx.

I I Fan DW, Kim HS, Birosca S, Coomna BC. Critical review of hot stamping technology for automotive steels. Materials Science and Technology. 2007;16-20.

12 Lechler J, Merklein M. Hot stamping of ultra high strength steels as a key technology for lightweight construction. Materials Science and Technology. 2008;1698-1709.

I3 Body \& Chassis Systems. Hot Stamping. 2014 [acesso em 13 jan. 20 I4]. Disponível em: http://www.magna.com/ capabilities/body-chassis-systems/innovation-technology/hot-stamping.

14 Costa RM, Henkin H. Estratégias Competitivas e Desempenho da Indústria Automobilística no Brasil. In: Associação Nacional dos Centros de Pós-Graduação em Economia. Anais do XL Encontro Nacional de Economia; 2012 Dezembro I I-I4; Porto de Galinhas, Brasil. Niterói: ANPEC; 2012 [acesso em 12 mar. 20 I4]. Disponível em: http://www.anpec.org.br/novosite/br/encontro-20I2.

15 Campo Grande P. Mudança de fase: teste Volkswagen UP! Revista Quatro Rodas. 2014;653.

16 ABM. Estampagem a quente: peças com geometria complexa e alta resistência estão em sintonia com o programa de avaliação de carros novos europeus. Revista Máquinas e Metais. 2014;70:194-196.

Recebido em: 12 Fev.2015

Aceito em: 28 Maio 2015 